\title{
JAIME II Y LA NUEVA CONCESIÓN DE TÍTULOS NOBILIARIOS EN LA ESPAÑA DEL SIGLO XIV
}

\author{
Francisco DE MOXÓ Y MONTOLIU \\ Universidad de San Pablo-CEU. \\ Madrid
}

Uno de los fenómenos más característicos de la historia de nuestro siglo XIV es la reanudación por parte de los monarcas peninsulares de la concesión de títulos nobiliarios, en desuso desde hacia largo tiempo respecto a los de marqués, duque o príncipe en los siglos de la reconquista(1). Nos proponemos en este trabajo recoger, ordenar y precisar algunos datos ya más o menos conocidos referentes a Aragón y Castilla que puedan servir de base para ulteriores reflexiones -aquí solamente apuntadas- sobre los orígenes y evolución de la nueva nobleza titulada de esos reinos bajomedievales en su relación con la monarquía, y en particular para mostrar la posición inicial de Jaime II en este proceso y asentar la prioridad temporal y el influjo que en esa evolución pudo tener la de la Corona Aragonesa.

\section{Titulos aragoneses}

Ya en otro lugar me referí al proceso de "domesticación" (la expresión es de Duby) de la nobleza aragonesa en el siglo XIV tras los turbulentos reinados de Jaime I, Pedro III y Alfonso III en el siglo XII|(2). Desde los comienzos de su reinado a fines de este mismo siglo (1291), Jaime II, a la vez que iniciaba una política de amplios vuelos en lo exterior, emprendió otra no menos decidida ("implacable" la llama Sobrequés(3)) de centralización y organización del poder en lo interior. Ambas conducirían en el siglo siguien- 
te, por lo que a la nobleza respecta, a una progresiva incorporación de la misma a las tareas de la Corona y a la creación en torno a los monarcas de una nueva nobleza titulada cuyos más altos escalones se situarían en el mismo seno de la familia real. Títulos nuevos en parte, o "resurrección" en otros casos de antiguos títulos de los primeros siglos de la reconquista, incorporados a la Corona en diversos momentos de la misma, o "adquiridos" simplemente para la familia real.

Jaime II inaugura esta política en la España del s. XIV con la concesión de tres títulos nobiliarios, con los señoríos correspondientes, para sus hijos los infantes Pedro y Ramón Berenguer. El primero recibiría los condados de Ribagorza (1322), incorporado a la Corona en tiempos pasados, y de Ampurias, conseguido en 1325 por permuta por territorios valencianos con su titular Hugo VI de Cardona. El segundo, el condado de Prades, de nueva creación (1324), que permutaría en 1341 con su hermana por el de Ampurias. Ya antes, el heredero -por renuncia del primogénito Jaime- el futuro Alfonso IV, había vinculado, por su matrimonio con Teresa de Entenza (1314), el condado de Urgel a la órbita de la Corona. Todo ello revelaba una política, si no idéntica, similar a la iniciada en Francia un siglo antes por Luis VIII y seguida luego en el reinado de su hijo Luis IX, tendente a crear una "cúpula nobiliaria" a base de miembros de la familia real. Facilitada en el caso de Jaime II por la numerosa prole habida de su esposa Blanca (m. 1310), nieta del conde de Provenza y luego rey de Nápoles Carlos de Anjou, hermano de san Luis. Pudo influir además el deseo de establecer en Cataluña una base nobiliaria más adicta frente a las agitaciones manifestadas desde el siglo anterior por los nobles aragoneses y la propia vieja nobleza catalana. $Y$ en el caso del renovado título condal de Ribagorza, la búsqueda de una solución "salomónica" para ese territorio, atribuido a los aragoneses en las Cortes de Zaragoza del 1300 y a los catalanes por un "capítol de Cort" (aunque no aprobado por el rey) de 1305; y aun distinguir con títulos y señoríos a un posible heredero de la Corona, dada la salud precaria tanto de su hermano el futuro Alfonso IV como el hijo de éste, Pedro.

Fallecido Jaime II (1327), su hijo y sucesor Alfonso IV crearía en 1330 , sólo a tres años de la muerte de su padre, el marquesado de Tortosa para el infante Fernando, hijo mayor de su segundo matrimonio con Leonor de Castilla(4). Se trataba del primer marquesado peninsular de la Baja Edad Media, reincorporado a la Corona en 1363 tras la muerte violenta de Fernando en Castellón. Pedro IV continuará el ritmo ascendente de esta política creando el ducado de Gerona para su primogénito varón el infante Juan en 1351(5). En cuanto a los títulos condales, en 1348, derrotada la Unión en Epila, Pedro IV había creado el condado de Luna en favor de su amigo de la infancia y fiel partidario D. Lope de Luna, tío político del rey por su matrimo- 
nio con la infanta Violante, hija menor de Jaime II(6). Esta circunstancia obliga a matizar la afirmación de Zurita de que dicho título fuera "el primero que se sabe en estos reinos haberse dado a ricohombre que no fuese hijo de rey"(7); ya que, aunque así fue, el enlace con la familia real lo insertaba en la línea de la política iniciada por Jaime II. Luego lo heredaría la hija mayor de D. Lope, María de Luna, que al casar con el infante Martín (futuro Martín I) introduciría de lleno el título en la Casa Real(8).

En Cataluña crearía Pedro IV los tres condados de Cervera (1353), Osona (1355) y Cardona (1375); y otros tantos en Valencia: los condados de Denia (1356), Morella (1366) y Xérica (1372). Veamos también la relación de estos nuevos títulos con la Casa Real.

El condado de Cervera se creó como anejo al ducado de Gerona, vinculado como hemos dicho al primogénito Juan desde dos años antes, pasando luego al subir este al trono a sus hijos Pedro y Jaime sucesivamente. Los de Osona y Cardona, aunque no concedidos a miembros de la familia real, recaerian como el aragonés de Luna en personajes unidos a ella por próximo parentesco. El de Osona en Bernardo III, ya vizconde de Cabrera y casado con Margarita de Foix y de Luna, sobrina por línea paterna y materna respectivamente del infante Pedro, conde de Ribagorza (marido de Juana de Foix) y del conde D. Lope de Luna (hermano de su madre Constanza(9) ). El de Cardona, elevación a condado del antiguo título vizcondal, fue otorgado a Hugo Folch II, que había casado en primeras nupcias con Blanca de Aragón, hija del infante Ramón Berenguer, conde de Prades y luego de Ampurias, y prima por tanto del rey.

En cuanto a los títulos valencianos, el condado de Denia fue otorgado a D. Alonso de Aragón, primo del rey como hijo del infante Pedro, conde de Ribagorza y de Prades. Sus dominios levantinos se verían ampliados luego considerablemente al recibir de Enrique II de Castilla el marquesado de Villena (1366) y posteriormente el ducado de Gandía de Martín I de Aragón $(1397)^{(10)}$. Este, por su parte, siendo todavía infante, había recibido de su padre Pedro IV en 1366 el recién creado condado de Morella(11) y en 1372 el de Xérica, elevado el señorío a condado al extinguirse la línea descendiente del hijo legitimado de Jaime I, Pedro de Xérica(12). Los dominios de D. Martín quedaron bien redondeados por su boda con María de Luna, hija y heredera de D. Lope, que, además del condado de Luna en Aragón, aportó en su matrimonio (1372) el señorío de Segorbe y otros lugares de los reinos de Aragón y Valencia, formando el que se conocería en éste con el nombre de "Real Patrimonio" (13). Todavía en 1387 Martín recibiría en Cataluña de su hermano Juan I el ducado de Montblanch, de nueva creación, con lo que los títulos y dominios del futuro rey se extenderían a todos los territorios peninsulares de la Confederación(14). 


\section{Títulos castellanos}

Si consideramos ahora los títulos otorgados por los reyes de Castilla en la misma centuria, observamos que en la primera mitad del siglo aparece como único el de conde de Trastámara (1325), con Lemos y Sarria, concedido por Alfonso XI a su privado Alvar Nuñez Osorio. Muerto éste luego por orden del rey en 1329 , fue otorgado de nuevo por el mismo, en fecha difícil de precisar entre 1334 y 1350, a su hijo bastardo Enrique. Todos los demás títulos corresponden a la segunda mitad del siglo. Coronado Enrique rey de Castilla en Burgos en 1366, en los tres años que siguieron hasta el del fratricidio de Montiel que puso fin a la guerra (1369), asistimos a una verdadera proliferación de títulos, la mayoría de los concedidos en este siglo, otorgados tanto a sus familiares más próximos (sus hermanos Sancho, conde de Alburquerque, y Tello, conde de Vizcaya (15), sus hijos bastardos Alfonso Enríquez, conde de Noreña, y Fadrique, duque de Benavente (16) y su pariente Juan Sánchez (17), conde de Carrión) como a los que, procedentes de otros reinos, le habían servido en la guerra, como Beltrán Duguesclín, Alfonso de Aragón, Hugo de Calveley, Bernal de Bearne y Pierre de Vilaines, a los que concedió respectivamente los títulos de duque de Molina, marqués de Villena, y condes de Carrión, Medinaceli (18) y Ribadeo. Todavía en 1371 concedería de nuevo Trastámara como condado (título obtenido antes brevemente con carácter ducal por Beltrán Duguesclín) a su sobrino Pedro, hijo de su hermano el maestre de Santiago D. Fadrique, que lo ostentaría hasta su muerte en 1399 (19). Entre los parientes del rey debe contarse también al primer conde de Niebla (1368), Juan Alfonso de Guzmán, primo segundo de la madre de Enrique II Leonor y casado sucesivamente con Juana, sobrina, y Beatriz, hija del mismo monarca (20).

Pocos títulos más concederían sus sucesores Juan I y Enrique III; casi todo oriundos de Portugal, en el marco de las luchas por el trono de aquel país desarrolladas en las postrimerías del siglo. Así el de Valencia de Campos, otorgado por Juan I con categoría de ducado al infante Juan de Portugal y de condado después (transformado poco a poco el nombre en el de Valencia de don Juan) a Martín Vázquez de Acuña, yerno de aquél (1387) (21). E igualmente el de Benavente, ya concedido antes con categoría ducal por Enrique II a su hijo D. Fadrique, y ahora, tras su reversión a la Corona cuando D. Fadrique fue puesto en prisión, otorgado de nuevo como condado (1398) por Enrique III a Juan Alonso Pimentel. Sólo el título de conde de Mayorga (1381) concedido por Juan I a Pedro Núñez de Lara, último vástago del linaje, no recaería en un extranjero (22).

Mencionemos también por último la creación por Juan I del Principado de Asturias (1388), acompañado del ducado de Soria, a favor de su heredero el futuro Enrique III, con ocasión de la boda de éste con Catalina de Lancaster. 


\section{Análisis sincrónico}

Si comparamos ahora los títulos aragoneses con los otorgados por los reyes castellanos veremos aparecer la posición claramente prioritaria que ocupan las concesiones de Jaime II, y aun de sus sucesores luego, respecto a los títulos castellanos. Para ello puede sernos útil la siguiente visión de conjunto de los concedidos en uno y otro reino en el siglo XIV.

\section{ARAGON \\ Jaime II (1291-1327)}

1322 C. Ribagorza (renov.) Inf. Pedro

1324 C. Prades

1325

C. Ampurias (renov.)
Inf. R. Berenguer

Int. Pedro
CASTILLA

Alfonso XI (1312-1350)

\section{Alfonso IV (1327-1336)}
1330 M. Tortosa
Inf. Fernando
1334 Pr. Villena
D. Juan Manuel 1334

1325 C. Trastámara (I) A. Núñez Osorio Lemos y Sarria A. Núñez

(1336: 0 D.)

\section{Pedro IV (1336-1387)}

1348 C. Luna

D. Lope de Luna

\section{Enrique (hijo del rey)}

1350

\begin{tabular}{|c|c|c|c|}
\hline 1351 D. Gerona & Inf. Juan & \multicolumn{2}{|c|}{ Pedro I (1350-1369) } \\
\hline 1353 C. Cervera & Inf. Juan & & \\
\hline \multirow[t]{2}{*}{1356 C. Denia } & Altonso de Aragón & & \\
\hline & (primo real) & 1366 D. Trastámara (III) & Fdo. de Castro \\
\hline 1356 C. Osona & Bern. III Cabrera & \multicolumn{2}{|c|}{ Enrique II (1366-1379) } \\
\hline 1366 C. Borja & B. Duguesclín & 1366 D. Trastámara (IV) & B. Duguesclín \\
\hline \multirow[t]{7}{*}{1366 C. Morella } & Inf. Martín & 1366 M. Villena & Alfonso de Aragón \\
\hline & & 1366 C. Alburquerque & Sancho (hno. del rey) \\
\hline & & 1366 C. Noreña & Alt. Enríquez \\
\hline & & & (Hijo del rey \\
\hline & & 1366 C. Carrión (I) & Hugo de Calveley \\
\hline & & 1366 C. Vizcaya & Tello y Castañeda \\
\hline & & & (hno. del rey) \\
\hline
\end{tabular}


1368 C. Carrión (II)

Juan S. Manuel

1369 D. Molina B.

Duguesclín

1369 C. Ribadeo

P. Vilaines

1371 C. Trastámara (V)

Pedro (sobrino rey)
1372 C. Xérica
Int. Martín
1375 C. Cardona
Hugo Folch II

Juan I (1387-1396)

1387 D. Montblanch

Int. Martín
Juan I (1379-1390)

1381 C. Mayorga

P. N. Lara

1387 D. Valencia de C. (I) Inf. Juan de Portuga y C. de Alba

Martín (1396-1410)

1397 D. Gandía
A. de Aragón
(tío $2^{\circ}$ del rey)

\section{Enrique III (1390-14:06)}

1392 C. Valencia D. Juan

(II) M. V. de Acuña

1398 C. Benavente (II)

J. Alonso Pimentel

Es interesante ante todo observar que el primero de los títulos castellanos, el condado de Trastámara otorgado por Alfonso XI a Alvar Núñez Osorio (1325), sigue inmediatamente a las concesiones de títulos condales hechas por Jaime II en favor de los infantes Pedro (1322 y 1325) y Ramón Berenguer (1324). Título el de Trastámara único concedido por Alfonso Xl, que, tras su efímera posesión por Alvar (m. 1329), es otorgado de nuevo más tarde por el mismo rey a su hijo bastardo Enrique, en fecha no precisada entre 1334 y 1350.

Entretanto en Aragón vemos aparecer por vez primera el título de marqués (si exceptuamos como dijimos el antiguo "comes et Marchio" de los condes de Barcelona) en la historia peninsular, concedido en 1330 por Alfonso XI a su hijo Fernando, marqués de Tortosa. $Y$ aun el primer título marquesal castellano, el de Villena, concedido 36 años más tarde por Enrique II, lo será también a un miembro de la casa real de Aragón, Alfonso, primo hermano de Pedro IV y conde ya de Denia y duque luego de Gandía en el reino de Valencia. Por cierto que este mismo título de Villena había sido otor- 
gado ya anteriormente como principado (1334) por Alfonso IV de Aragón al que fuera su yerno D. Juan Manuel de Castilla, cuando se trató de la boda de la hija de éste con el mencionado marqués de Tortosa. Dos años después Pedro IV dió opción a D. Juan Manuel entre principado o ducado, aunque parece que ninguna de estas concesiones llegó a hacerse efectiva (23).

Si prescindimos de ello, el primer título ducal lo vemos igualmente aparecer en el reino aragonés, con la concesión del ducado de Gerona al primogénito varón de Pedro IV el infante Juan a raíz de su nacimiento, inagurando así en la península la costumbre -ya existente en Inglaterra y Franciade otorgar un título peculiar al heredero de la corona, que su cuñado Juan I de Castilla seguirá muchos años más tarde con la creación del principado de Asturias.

\section{Consideraciones finales}

Los límites que nos hemos propuesto en este trabajo no nos permiten alargarnos demasiado en consideraciones sin duda interesantes a que los datos aquí expuestos y ordenados se prestan. Pero quisiéramos apuntar, siquiera brevemente, algunas de ellas.

En primer lugar, creemos que no se trata de títulos cuyo valor fuera "puramente simbólico". El propio prof. Valdeón, que así lo afirma hablando de los concedidos por Enrique II, reconoce a renglón seguido que "de hecho incrementaba de manera notable el prestigio del monarca" (24). Ni conviene olvidar las amplias concesiones territoriales que normalmente llevaban aparejados. Se trata de una política de "apanages" que en general (salvo en el caso del condado de Urgel) se mueve en sentido contrario a la del modelo francés del siglo anterior, tendente a incorporar a la familia real, mediante enlaces matrimoniales, los grandes títulos y señoríos territoriales, pero que coincide con la más reciente de otorgar títulos y señoríos a los parientes más próximos del rey. Concesiones que, aunque parecen a primera vista mermar los territorios de la Corona, en realidad tienden a rodear a ésta de un amplio escudo familiar de nobleza titulada unida estrechamente a ella por los vínculos de la sangre, aun con los peligros innegables de intromisión inmoderada en las tareas específicas de la gobernación del rey.

En segundo lugar llama la atención la proliferación de concesiones de títulos a extranjeros en Castilla, perfectamente explicables por las circunstancias de las guerras civil y castellano-portuguesa de la segunda mitad del siglo, mientras en Aragón apenas si se registra otra que la, al parecer efímera, del condado de Borja a Duguesclín. A lo que cabría añadir los títulos otorgados a personajes "a caballo", según la feliz expresión del prof. Mitre, de los distintos reinos peninsulares, como D. Juan Manuel y D. Alonso de 
Aragón, y los de Acuña y Pimentel entre Portugal y Castilla. Todo ello tendente en general, no sólo a recompensar simplemente servicios prestados, sino también en muchos casos atraer a la órbita de la propia corona a figuras destacadas de otra, asegurando al propio tiempo los límites fronterizos.

Cabría preguntarse finalmente el por qué de esa prioridad en el tiempo de la Corona aragonesa en las nuevas concesiones de títulos del siglo XIV ¿Fue simplemente casual? ¿Obedeció, aparte de las circunstancias ya señaladas al hablar de Jaime II, a dos diversas concepciones de la política de fortalecimiento del poder real por parte de los monarcas aragoneses anteriores a 1366 respecto a los castellanos? ¿O a una mayor afinidad con lo ultrapirenaico? En todo caso, y a la vista de los datos aquí expuestos y debidamente ordenados y relacionados entre sí, lo que no deja de resultar sorprendente es que un ilustre genealogista de la talla de Fernández de Bethencourt haya podido afirmar que Alfonso XI, y sobre todo Enrique II, habían iniciado la concesión de títulos en la España del siglo XIV(25); y otros autores más recientes parezcan ignorar o minimizar la prolongada y profunda conexión del primer Trastámara con la Corona aragonesa antes de subir al trono de Castilla, atribuyendo la subsiguiente eclosión de títulos nobiliarios simplemente al influjo francés.

En éste, como en tantos otros temas, se echa de menos una visión más equilibrada de la historia de la España medieval, no centrada desmesuradamente, con inflacción del escenario propio, en uno u otro de los reinos peninsulares, sino penetrada de una constante y atenta consideración de su interrelación y recíprocos influjos. Una labor más ardua sin duda, tanto por el más vasto horizonte a cuyo examen obliga como por la ponderada ecuanimidad que postula, pero que constituye un reto permanente para todo historiador. 


\section{NOTAS}

(1) Prescindimos del antiguo "comes et marchie" de origen carolingio, de los condes de Barcelona, asi como del de "princeps" que posteriormente, respecto a Aragón, usó Ramón Berenguer IV, y respecto a Cataluña, connotando soberania les fue atribuido por los romanistas. No tratamos aqui de los vizcondados, en su mayoría catalanes de raíz antigua salvo el nuevo valenciano de Xelva, concedido en 1390 por Juan I a Ramón Lladró de Vilanova i Boïl (cf. J. PASTOR I FLUIXÀ, "Nobles i cavallers al País Valencià" , Saitabi XLIII (1993), p. 24). Las baronías, particularmente numerosas en el reino de Valencia, merecerian un estudio pormenorizado todavía por realizar.

(2) F. de MOXÓ, "La Casa de Luna", Münster 1990, pp. 314-319.

(3) S. SOBREQUÉS, "Els barons de Catalunya", Barcelona, 1970, p. 95.

(4) Aunque en el Estatuto de Daroca (1328) Alfonso IV habia jurado no enajenar territorio alguno de la Corona en el plazo de 10 años, Leonor obtuvo un rescripto de la Santa Sede absolviéndole de su juramento respecto a ella y a sus hijos. Al marquesado de Tortosa se unió el señorío jurisdiccional de Camarasa y la baronía de Fraga. El señorío de Camarasa, segregado de Urgel a instancias de la propia reina Leonor, pasaría más tarde al infante D. Martín (1368), quien en 1392 lo cedió a su esposa María de Luna. Vendido por ésta a la ciudad de Lérida, retornó a la Corona en 1414. Tras diversas vicisitudes pasó a los Luna, señores de Ricla, otorgando Carlos $V$ el título marquesal en 1543 a Francisca Luisa de Luna y su esposo Diego de los Cobos y viniendo a pasar finalmente a la Casa Ducal de Medinaceli que hoy lo ostenta.

(5) Al subir Juan $\mid$ al trono en 1387 lo otorgaria sucesivamente a sus hijos Jaime (1387-1388) y Pedro (1394), fallecidos en la infancia. Más tarde Fernando I lo elevaría a principado en favor de su primogénito el futuro Alfonso $\mathrm{V}$.

(6) "La Casa de Luna", pp. 186 y ss. y 199 ss. En Epila estaba también, junto a D. Lope de Luna, Bernardo II de Cabrera al frente de las tropas reales. Bernardo II, vizconde que fuera de Cabrera hasta 1342, fue el gran privado de Pedro IV que le nombró ayo de su primogénito Juan apenas nacido éste (1350). Mucho antes de su ejecución por orden real en 1364 había renunciado al vizcondado de Cabrera en su hijo Poncio IV (1342) y más tarde el de Osona, de nueva creación, en su segundo hijo Bernardo III (1356) del que hablamos enseguida.

(7) Zurita, An. VIII, 31.

(8) Ya reyes de Aragón Martín y María, heredaría luego el título condal de Luna su nieto Fadrique -hijo natural de Martín de Sicilia- hasta ser desposeído del mismo por 
Alfonso $V$ en 1340, aunque lo siguió ostentano en Castilla hasta su muerte en 1438, preso en Brazuelos. Revirtió asi el título a la corona hasta su concesión a la Casa Ducal de Villahermosa.

(9) "La Casa de Luna", tablas geneal. IV y XII. A la muerte de Bernardo III (1368), el condado de Osona volvió a la Corona reintegrándose en el ducado de Gerona. Su hijo Bernardo IV, vizconde de Cabrera y de Bas, recibiría en 1393 de los reyes de Sicilia Martín y María el título de conde de Módica, confiscada a los Chiaramonte. Ver S. Sobrequés, o.c., pp. 171-174.

(10) Aunque al mismo tiempo su marquesado de Villena era reincorporado a la Corona de Castilla. Ver L. Suárez, "Nobleza y Monarquia", Valladolid, 1975, p. 85, n. 30.

(11) El primer titular del señorio de Morella habría sido el infante Alfonso, hijo menor de Pedro IV y Leonor de Sicilia, nacido en 1362 y fallecido niño al ser entregado como rehén a Enrique de Trastámara en virtud del Tratado de Monzón entre éste y Pedro IV de 1363. Ver R. TASIS. "Joan I, el rei caçador i músic", Barcelona1959, p. 74.- $P$. Aguado Bleye, en su "Manual de Historia de España", lo confunde con Pedro, hijo de Sibila de Fortià (I, p. 813).

(12) El señorío de Xèrica, concedido por Jaime I a su hijo legitimado Jaime y sus descendientes, habia quedado vacante en 1369 al morir Juan Alfonso de Xérica, reincorporándolo Pedro IV a la Corona en virtud del vínculo testamentario de Jaime I. Ver M. COSTA "La Casa de Xérica i la seva política en relación amb la monarquia de la Corona d'Aragó", Tesis doctoral inédita, Barcelona, 1990, pp. 288, 291 y 302.

(13) Aurea L. JAVIERRE, "María de Luna, reina de Aragón", Madrid, 1942, p. 9.

(14) ZURITA, An. X, 3; en Cataluña poseía ya D. Martín desde 1368 el condado de Besalú, unido al condado de Barcelona desde 1111.

(15) Así en SUÁREZ, o. c., p. 24. Salazar y Castro, "casa de Lara", t. I, p. 405 habla sólo de "señoríos " y "tierra".

(16) "Fue ducado mientras lo tuvo en señorío un personaje de sangre real, Fadrique de Trastámara. Al pasar luego a un portugués, Juan Alfonso de Pimentel, lo fue sólo como condado". Ver MITRE, "Evolución de la nobleza en Castilla bajo Enrique III", Valladolid, 1968, p. 24, n.7.

(17) S. de MOXÓ, "De la nobleza vieja a la nobleza nueva", Cuad. de Historia, III (1969), p. 189 y 193.

(18) J. VALDEÓN, "Enrique II de Castilla", Valladolid, 1966, pp. 192 y 282.

(19) Sobre el ducado o condado de Trastámara ver MOREL FATIO, A., "La donation du duché de Molina a Bertrand du Guesclin", Bibliothèque de l'Ecole des Chartres, LX, Paris, 1899, pp. 146-147. Contra lo afirmado por el canciller Ayala, opina que la concesión del ducado de Molina sería posterior en 3 años a la del de Trastámara. En cuanto al carácter ducal o condal de éste, sostiene el primero, basado en dos documentos de enero (Segovia) y septiembre (Burdeos) de 1367, recogidos por Colmenares, en que Bertrán así se titula. Y recuerda como, simultáneamente, fue concedido por Pedro I a su alférez mayor Fernando de Castro (Salazar de Mendoza y López de Haro se inclinan por el carácter condal del título -que llevaba aparejados los de Lemos y Sarrià-en todos los casos) Cf. L.V. DIAZ MARTÍN, "Itinerario de Pedro I de Castilla", Valladolid, 1975, Reg. doc. 931. Sobre una posible relación anterior a Molina-Trastámara, ver Salazar y Castro, libro IV, p. 247. Los condados separados de Trastámara y Lemos volverían a la 
familia Osorio, del que fuera en 1325 su primer titular, en tiempos de Juan II y Enrique IV, respectivamente: S. de MOXÓ, "De la nobleza vieja...", pp. 161-162.

(20) M.A. Ladero, "Niebla, de reino a condado", Madrid, 1992, p. 61.

(21) El infante D. Juan era hermano del difunto rey Fernando I de Portugal y había casado con una hija ilegítima de Enrique II de Castilla, Constanza. María, hija de ambos, fue esposa de Martín Vázquez de Acuña. El nuevo nombre de Valencia de don Juan parece se debió a dicho primer titular, si bien otros lo han atribuído al hecho de haber sido anteriormente señor de la villa el infante Juan de Castilla, hijo tercero de Alfonso $X$ el Sabio. Cf. F. FERNÁNDEZ DE BETHENCOURT, "Historia genealógica y heráldica de la monarquía española, casa real y grandes de España", T. 2, pp. 131-139. D. Juan de Portugal había recibido antes el título de conde de Alba: L. SUÁREZ, "Historia del reinado de Juan I de Castilla", Madrid, 1977, p. 319.

(22) SALAZAR Y CASTRO, "Casa de Lara”, t. III, p. 216.

(23) Ver mi trabajo "La relación epistolar entre Alfonso XI y Alfonso IV en el ACA" en "En la España medieval", vol. 3 (1982), p. 192, n. 12; y "La Casa de Luna", pp. 180 y 503 (doc. 266). Sobre el anómalo status político-jurísdiccional de Villena, que desde 1304 hasta 1364 perteneció en cuanto a la propiedad al castellano D. Juan Manuel y sus parientes, pero bajo la jurisdicción señorial del rey de Aragón, ver los trabajos de Juan Manuel del ESTAL, "Vaivén político del señorío de Villena entre Castilla y Aragón (siglos XIII y XIV)" y A. PRETEL, "El cambio dinástico y la crisis de mediados del s. XIV en el señorio de Villena" en el Congreso de Historia del Señorío de Villena, celebrado en Albacete en 1986 (ed. Instituto de EE. Albacetenses, 1987).

(24) J. VALDEÓN, "Enrique II de Castilla", p. 118.

(25) F. FERNÁNDEZ DE BETHENCOURT, "Historia genealógica y heráldica de la Monarquía española, Casa Real y grandes de España", T. 2, p. 26, bajo el título "Origen de los primeros títulos de España": "Es en realidad en pleno siglo XIV, y en el reinado del sucesor de Don Pedro, cuando comienzan los títulos de duque, marqués y conde a ser transmisibles y hereditarios en las familias... Había ya Don Alfonso XI restablecido la dignidad condal..." (p. 27). Es cierto que parece referirse a la "trasmisibilidad" o "hereditariedad", pero no puede decirse que hubiera en eso gran diferencia entre los aragoneses y los castellanos, de los cuales, dejando aparte el carácter fugaz (salvo Medinaceli) de los concedidos a extranjeros y aun a alguno de sus parientes, por Enrique II, ha podido afirmar L. Suárez que "en 1387 la alta nobleza creada por Enrique II se encontraba dispersa y rota ("Nobleza y Monarquía", p. 44). Por otra parte, las reintegraciones, por enlace matrimonial o por confiscación, a la Corona, no significan que los títulos no fueran transmisibles y hereditarios. Observamos de paso sólo 4 linajes (2 por cada reino), de la "nobleza Vieja" anterior al s. XIV, recibirán títulos: los ya antes vizcondes catalanes de Cabrera (C. de Osona) y Cardona (ahora conde) y en Castilla los de La Cerda (C. de Medinaceli) y Guzmán (C. de Niebla). Y de estos títulos sólo los tres últimos llegarán, por transmisión directa, a la Edad Moderna. 